\title{
Relapse rates after elective discontinuation of anti-TNF therapy in rheumatoid arthritis: a meta-analysis and review of literature
}

\author{
Arduino A. Mangoni ${ }^{1 *}$, Fahdah Al Okaily ${ }^{2}$, Hani Almoallim³ ${ }^{3}$ Seham Al Rashidi ${ }^{2}$, Reem Hamdy A. Mohammed ${ }^{4,5}$ and \\ Amal Barbary ${ }^{6}$
}

\begin{abstract}
Background: Inhibitors of tumor necrosis factor alpha (TNF-a) are current mainstay of therapies for rheumatoid arthritis (RA). The decision when to withdraw TNF-a inhibitors after achieving remission and the incidence of relapse rates with elective discontinuation are both important questions that demand intense survey in these patients. In this meta-analysis we aimed to estimate the magnitude of relapse rate after elective TNF-a inhibitor discontinuation in RA patients with remission.
\end{abstract}

Methods: Systematic searches of PubMed/MEDLINE, Cochrane Library databases, grey literature (unpublished and ongoing trials) from the WHO International Clinical Trials Registry Platform and the US National Institutes of Health were performed for studies reporting the outcomes of elective discontinuation of TNF-a inhibitor in RA patients after remission. Random-effects models for meta-analyses were conducted on extracted data.

Results: Out of 390 references screened, 16 RCTs were included. Meta-analysis of 1264 patient data revealed a relapse rate of 0.47 (95\% Cl $0.41-0.54)$. Sensitivity analysis showed that none of the studies had higher influence on the results.

Conclusions: Almost half of all the RA patients in remission relapse after elective TNF-a inhibitor discontinuation. This information might be useful when considering this management option with individual patients.

Keywords: DMARDs (synthetic), TNF-a inhibitors, Rheumatoid arthritis, Treatment discontinuation, Relapse

\section{Background}

Rheumatoid arthritis (RA) is a chronic multisystem autoimmune inflammatory disease that leads to significant joint inflammation with damage and deformity. The disease has an annual incidence of three cases per 10,000 , and a prevalence of $1 \%$, increasing with age and peaking between the ages of 35 and 50 years [1]. RA affects all populations, with few ethnic variations (e.g., 5$6 \%$ in some Native American groups vs. $0.8 \%$ in black-Caribbeans) [1, 2]. Women are affected three times more often than men however sex differences tend to diminish in older age groups with a female to male ratio of 2:1 after the fifth decade of life [1, 3].

\footnotetext{
* Correspondence: arduino.mangoni@flinders.edu.au

1 Department of Clinical Pharmacology, Flinders University and Flinders

Medical Centre, Bedford Park, SA 5042, Australia

Full list of author information is available at the end of the article
}

The pharmacological therapies for RA comprise nonsteroidal anti-inflammatory drugs (NSAIDs), corticosteroids and the disease-modifying antirheumatic drugs (DMARDs). The DMARDs include non-biologic (e.g. methotrexate) and biologic agents (TNF- $\alpha$ inhibitor drugs and non TNF- $\alpha$ biologics) that halt the progression of RA by reducing inflammation, preventing joint damage and maintaining the integrity of joints [1].

The TNF- $\alpha$ inhibitors etanercept, infliximab, certolizumab pegol, adalimumab, and golimumab, are a class of biologic DMARDs directed towards the TNF- $\alpha$ proinflammatory cytokine, and can be administered either subcutaneously or intravenously. TNF- $\alpha$ inhibitors have an established role in the induction and maintenance of remission in patients with RA [4]. However, suppression of TNF- $\alpha$ also leads to a range of adverse effects

(c) The Author(s). 2019 Open Access This article is distributed under the terms of the Creative Commons Attribution 4.0 International License (http://creativecommons.org/licenses/by/4.0/), which permits unrestricted use, distribution, and reproduction in any medium, provided you give appropriate credit to the original author(s) and the source, provide a link to the Creative Commons license, and indicate if changes were made. The Creative Commons Public Domain Dedication waiver (http://creativecommons.org/publicdomain/zero/1.0/) applies to the data made available in this article, unless otherwise stated. 
including the emergence of antinuclear antibodies (ANAs), generation of antibodies against these compounds, infections (including tuberculosis), increased risk of cancer, heart failure, demyelinating disorders, and bone marrow suppression [5]. Immunogenicity has been shown to occur in patients receiving adalimumab and infliximab, potentially leading to decreased drug efficacy [6]. The risk of developing such adverse events, the inconvenience of parenteral administration, and the high cost of these agents raised the possibility of elective withdrawal in RA patients with a considerable disease-free period and in whom the treatment objectives were achieved. However, the continuation of TNF- $\alpha$ inhibitor therapy, in RA patients in remission or low disease activity, increased the probability of sustained response (whether remission or low disease activity) and retarded radiographic progression in a number of published meta-analyses [7, 8]. Furthermore, the incidence of serious adverse events, serious infection, malignancy, and scores of improvement of tender and swollen joints were not significantly different between strategies favoring continuation and those with elective discontinuation after remission with almost half of the patients withdrawing biologicals maintaining low disease activity $[6,7]$.

Though elective TNF- $\alpha$ inhibitor discontinuation is justified in several RA patients, there is a lack of sufficient data to guide the decision. Further, the course of action post-withdrawal also remains to be understood, although a decision based on sustained remission has been proposed [9]. Nonetheless, a consensus about patient selection and the timing of withdrawal remains to be reached.

As an initial step to address these issues, we investigated whether TNF- $\alpha$ inhibitors can be withdrawn in general. To this end, we performed a meta-analysis of studies investigating the relapse rates after elective withdrawal of TNF- $\alpha$ inhibitor therapy in RA patients.

\section{Methods}

\section{Inclusion criteria}

1- Studies that included RA patients classified according to either the American Rheumatism Association 1987 revised criteria for the classification of RA or the 2010 American College of Rheumatology (ACR)/European League Against Rheumatism (EULAR) RA classification criteria were used $[10,11]$.

2- Studies that investigated the relapse rate following elective withdrawal of TNF- $\alpha$ inhibitors (adalimumab, certolizumab pegol, etanercept, golimumab, and infliximab) as a first line or non first line biologic in patients with RA.

\section{Literature search}

Literature search from the earliest available date to March 2016 was performed in PubMed/MEDLINE and the Cochrane Library databases, and grey literature (unpublished and ongoing trials) was assessed from the WHO International Clinical Trials Registry Platform (http://www.who.int/ictrp/en/) and the US National Institutes of Health (https://clinicaltrials.gov/) using the keywords "adalimumab" or "infliximab" or "golimumab" or "certolizumab pegol" or "etanercept" or "biological Products" and "Arthritis, Rheumatoid" and "withdrawal" or "withdrawn" or "discontinue" or "discontinuation" or "stop" or "stopped." The possibilities of finding all relevant publications were increased by not setting the limitations on language, year, or status during the initial search. The reference lists of included articles were also screened manually for additional studies. The commentaries and conference proceedings, however, were excluded.

\section{Data extraction and methodological quality assessment}

The reviewers (F. Alokaily \& S. AlRashidi) independently screened for potentially relevant article titles and abstracts based on the inclusion criteria. Also, full text articles were retrieved wherever necessary. Authors were involved independently in all stages of study selection and data extraction.

The methodological quality of each selected randomized study was assessed by the modified Jadad scale system [12]. The criteria for evaluation were: randomization, blinding, withdrawals, dropouts, inclusion/exclusion criteria, adverse effects, and statistical analysis. The evaluated scores of studies ranged from 0 to 5 points. A study with a score of $\geq 3$ was considered as of good quality. The quality of non-randomized trials was evaluated by CASP (The Critical Appraisal Skills Programme) checklist for Cohort study [13]. If $\geq 5$ of the questions in CASP provided positive results about a non-randomized trial, then the study was considered high quality.

\section{Statistical analysis}

Meta-analysis of the included studies was conducted using relapse rate with 95\% confidence interval (CI). Pooled relapse rate with $95 \%$ confidence interval was estimated incorporating fixed-effects model (based on the Mantel-Haenszel method) or random-effects model (based on the DerSimonian-Laird method) [14, 15]. Presence of heterogeneity was tested by Q-statistic [16] and quantified by $I^{2}$-index [17]. Q-statistic evaluated the presence of heterogeneity among the selected studies. Significant heterogeneity was marked by $p$-value of less than 0.05 . The $I^{2}$-index quantified the amount of heterogeneity among the selected studies. $I^{2}$ values of 25,50 and $75 \%$ suggested low, moderate and high degrees of heterogeneity, respectively. If there was no significant 
heterogeneity fixed-effects model was used; otherwise, random-effects model was used.

Sensitivity Analysis: To investigate the validity and robustness of meta-analysis the leave-one-out sensitivity method was applied to establish the robustness of the meta-analysis results.

Cumulative meta-analysis: Studies were included chronologically to identify the consistency in the result of selected studies.

Publication Bias: Publication bias was examined visually by producing a funnel plot where the standard error of the estimated event rates was plotted against the logit event rates [18]. If asymmetry in funnel plot was observed the trim and fill method was adopted to assess the impact of publication bias [19]. Ideally, approximately similar number of studies are expected to fall on either side of the plot. In case of asymmetry in the number of studies plotted, the trim and fill method plots the possibly missing studies. The number of missing studies plotted correlates proportionately with the publication bias.

All meta-analyses were executed using the Comprehensive Meta-analysis Software, Version 2 (Biostat, Englewood, NJ, USA).

\section{Results}

A total of 390 citations were identified from all databases. Screening excluded 351 abstracts, reviews and unpublished trials without results. After a further screening of titles and abstracts, 13 citations were excluded because of inappropriate protocols or outcomes. Out of 26 studies, 10 appeared to be duplicates. Thus, 16 studies ( $n=13$, published and $n=3$, unpublished) were finally eligible (Fig. 1; Tables 1 and 2). Ten studies were conducted in Europe, five were conducted in Japan, and one was conducted in Europe, Latin America, Asia and Australia. Seven studies were randomized, seven were observational/prospective, whereas the remaining two were retrospective (Table 1). Criteria for TNF- $\alpha$ inhibitor withdrawal were based on the DAS28/44 scoring system in 11 studies, clinical parameters in one study, and undefined in four studies. Duration of follow-up after withdrawal was $\geq 12$ months in 12 studies, and $<12$ months in the remaining four studies (Table 2).

The Jadad score was 3 in four out of the five identified RCTs, and 2 in the remaining RCT by Moghadam et al. (Table 3). The different score in the study by Moghadam et al. was due to its open label randomized study design. All non-RCTs were of high quality (Table 4).

The meta-analysis, conducted in 1264 RA participants from 16 studies, showed that the pooled relapse rate after elective withdrawal of anti-TNF therapy was 0.47; 95\% CI 0.41-0.54 (Fig. 2). As significant heterogeneity was observed (Cochrane's Q-statistics $=48.27 ; p$-value: 0.00 and $\mathrm{I}^{2}=68.92 \%$ ), a random-effects-model was used.

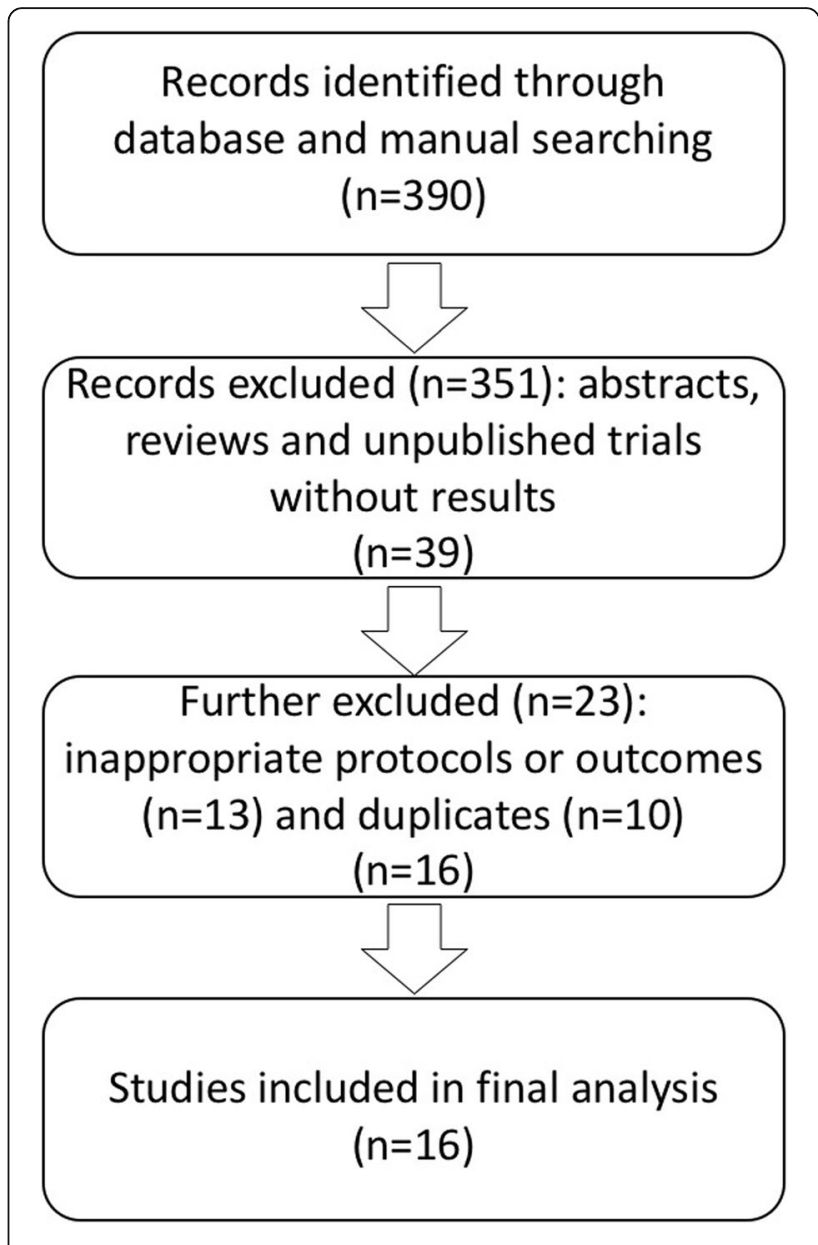

Fig. 1 Flowchart for identification of studies used

Sensitivity analysis, assessing the influence of individual studies on the pooled relapse rate by omitting individual studies at each step, suggested that no individual study significantly affected the pooled relapse rate, thus confirming the robustness of the meta-analysis results (Fig. 3).

Cumulative meta-analysis of the 16 studies showed that subsequent studies increased the precision of the point estimation (Fig. 4). No substantive change occurred in the direction or magnitude of the estimation.

The shape of the funnel plot did not reveal a clear evidence of asymmetry, suggesting no publication bias (Fig. 5). Furthermore, imputation plotted no missing studies on the right side. The trim and fill method, adopted to assess the impact of publication bias, showed that the point estimate and $95 \%$ confidence interval for the combined relapse rates remained unchanged after trim and fill test $(0.45 ; 95 \% \mathrm{CI}=$ $0.38-0.51)$.

\section{Discussion}

The current pharmacological treatment of RA is based on early intensive therapy with synthetic DMARDs in order to achieve clinical remission. If the latter is not 
Table 1 Study characteristics

\begin{tabular}{|c|c|c|c|c|}
\hline \multirow[b]{2}{*}{ S.No } & \multicolumn{4}{|l|}{ Study characteristics } \\
\hline & Study & Region & Type of study & $\begin{array}{l}\text { Source of } \\
\text { funding }\end{array}$ \\
\hline 1 & Quinn et al., 2005 & Europe (United Kingdom) & Randomized controlled trial & Not disclosed \\
\hline 2 & Nawata et al., 2008 & Asia (Japan) & Observational/prospective & Government \\
\hline 3 & Brocq et al., 2009 & Europe (France) & Observational/prospective & Not disclosed \\
\hline 4 & Tanaka et al., 2010 & Asia (Japan) & Observational/prospective & Government \\
\hline 5 & $\begin{array}{l}\text { van den Broek et al., } \\
2011\end{array}$ & Europe (Netherland) & Randomized, multicenter, single blind & Not disclosed \\
\hline 6 & $\begin{array}{l}\text { van der Maas et al., } \\
2012\end{array}$ & Europe (Netherland) & Observational/prospective & Not disclosed \\
\hline 7 & Harigai et al., 2012 & Asia (Japan) & Observational/retrospective & Government \\
\hline 8 & Hirata et al., 2013 & Asia (Japan) & Observational/prospective & Government \\
\hline 9 & Smolen et al., 2013 & Europe, Latin America, Asia, Australia & Randomized controlled trial & Industry \\
\hline 10 & Iwamoto et al., 2014 & Asia (Japan) & Observational/prospective & Not disclosed \\
\hline 11 & Kádár et al., 2014 & Europe (Hungary) & Retrospective, multicenter, cohort & Government \\
\hline 12 & Tanaka et al., 2015 & Europe (Hungary) & Observational/prospective & Government \\
\hline 13 & $\begin{array}{l}\text { Moghadam et al., } \\
2016\end{array}$ & Europe (Netherland) & $\begin{array}{l}\text { Randomized controlled trial, multicenter, } \\
\text { open label }\end{array}$ & Government \\
\hline 14 & $\begin{array}{l}\text { NCT00808509 } \\
\text { (ADMIRE) }\end{array}$ & Europe (Sweden) & Randomized, parallel group, open label & Industry \\
\hline 15 & $\begin{array}{l}\text { NCT00858780 } \\
\text { (DOSERA) }\end{array}$ & $\begin{array}{l}\text { Europe (Denmark, Finland, Hungary, Iceland, Norway, } \\
\text { Sweden) }\end{array}$ & Randomized controlled trial, double blind & Industry \\
\hline 16 & $\begin{array}{l}\text { NCT00858780 } \\
\text { (DOSERA) b }\end{array}$ & Europe (Denmark, Finland) & Randomized controlled trial, double blind & Industry \\
\hline
\end{tabular}

met, further options include increasing the dose of DMARD, adding another synthetic DMARD, or combining the original DMARD with a biologic agent such as TNF- $\alpha$ inhibitors [1]. However, professional guidelines do not provide clear recommendations regarding management strategies once remission, or stable low disease activity, is achieved [1]. Similarly, there is a limited amount of evidence regarding whether, when, how and in whom TNF- $\alpha$ inhibitors can be safely and effectively withdrawn in this context.

In addition to the achievement of remission or stable low disease activity, reasons for TNF- $\alpha$ inhibitor treatment discontinuation include patient preference, cost issues, and adverse effects. Patient surveys have reported that the lack of efficacy and injection reactions, e.g. pain, burning, discomfort, redness, and swelling, were the main factors responsible for treatment discontinuation [20]. However, the uncertainty regarding the magnitude of the overall risk of relapse is an important issue when discussing the option of TNF- $\alpha$ inhibitor treatment withdrawal with RA patients. The availability of robust data regarding the relapse rate in these patients might assist with treatment decisions, as well as informing future guidelines on RA management. This is particularly so as TNF- $\alpha$ inhibitor withdrawal is particularly common in clinical practice. Ramiro et al., investigated the self-reported discontinuation rates of anti-TNF drugs in RA patients $(n=2225)$ in the National Data Bank for Rheumatic Disease, a longitudinal observational study of RA outcomes [21]. Discontinuation of the first TNF- $\alpha$ inhibitor was observed in 1069 (48.0\%) of RA patients, with an annual rate of discontinuation of 0.17 (95\% CI 0.16 to 0.18 ). Out of 988 patients who started a second TNF- $\alpha$ inhibitor, 481 (48.7\%) reported treatment withdrawal, with an annual discontinuation rate of 0.19 (95\% CI 0.17 to 0.21 ). Older age, smoking, higher comorbidity index, and a higher score of the poly-symptomatic distress scale at baseline independently predicted treatment discontinuation, whereas the concomitant treatment with methotrexate reduced the probability of discontinuation [21]. Similar discontinuation rates have been reported in other observational studies [22, 23].

Our meta-analysis of 16 RCTs on RA patients showed a relatively high $(47 \%)$ pooled relapse rate after complete elective withdrawal of TNF- $\alpha$ inhibitors. There was significant heterogeneity among studies, however sensitivity analysis ruled out the influence of individual studies on the pooled relapse rate. Furthermore, barring one RCT, all identified studies were considered as having a high methodological quality, i.e. a clearly defined study aim, 
Mangoni et al. BMC Rheumatology

(2019) 3:10

Page 5 of 11

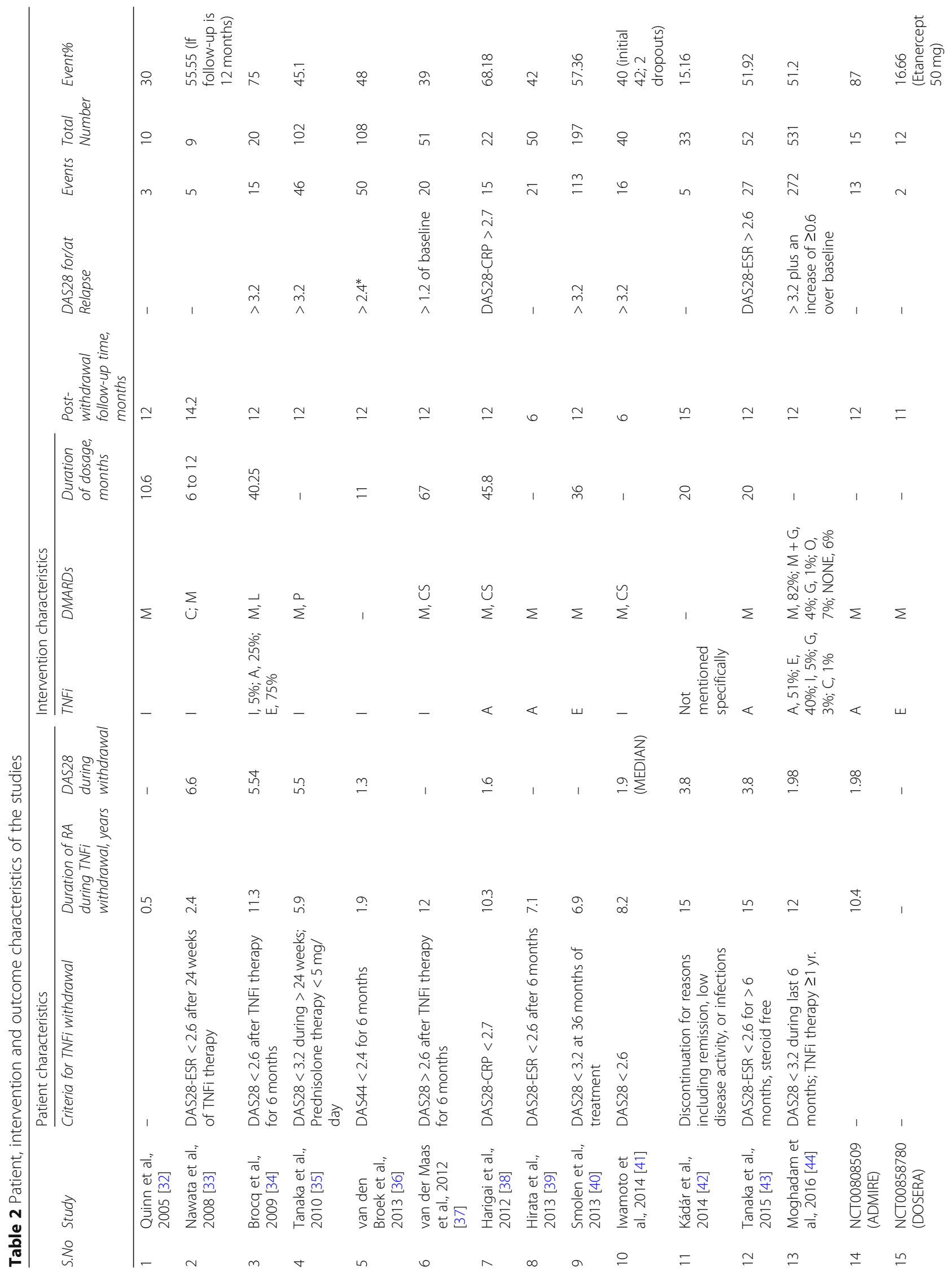


Mangoni et al. BMC Rheumatology

(2019) 3:10

Page 6 of 11

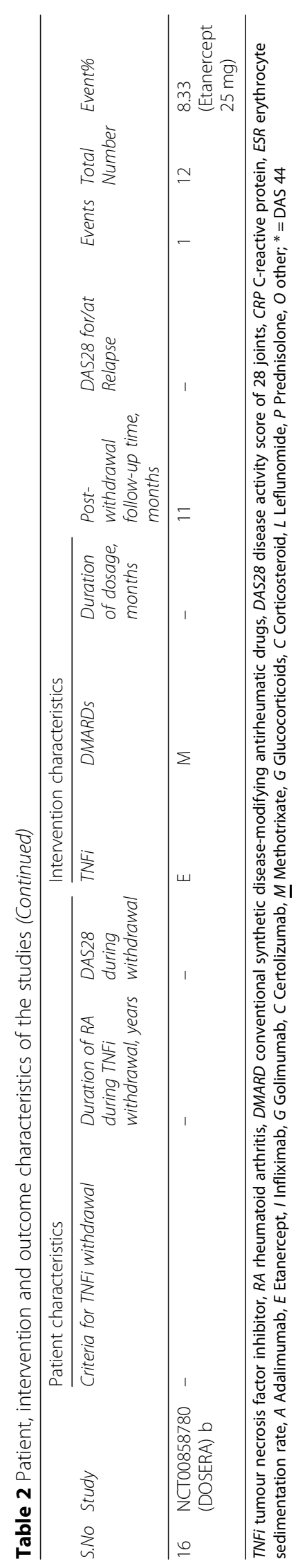


Table 3 Jadad score for the RCTs

\begin{tabular}{llllll}
\hline SI No. & Study Name & Question 1 & Question 2 & Question 3 & Total Score \\
\hline 1 & Quinn et al., 2005 & 1 & 1 & 1 & $\mathbf{3}$ \\
2 & Smolen et al., 2013 & 1 & 1 & 1 & $\mathbf{2}$ \\
3 & Moghadam et al., 2016 & 1 & 0 & 1 & $\mathbf{3}$ \\
5 & NCTO0858780 (DOSERA) & 1 & 1 & 1 & $\mathbf{3}$ \\
\hline
\end{tabular}

population, exposure, follow-up and unbiased assessment at the study end-point. In another recent systematic review and meta-analysis by Kuijper et al. the estimated relapse rates were 0.26 (95\% CI 0.17 to 0.39 ) for high-quality studies and 0.49 (95\% CI 0.27 to 0.73 ) for moderate-quality studies. However, unlike our study, focused on complete withdrawal of TNF- $\alpha$ inhibitors, the meta-analysis by Kuijper et al. also included studies reporting dose tapering [24].

A meta-analysis of six trials reported that TNF- $\alpha$ inhibitor treatment continuation, in RA patients in sustained remission or low disease activity, increased the probability of low disease activity (relative risk $[R R]=$ $0.66,95 \%$ CI $0.51-0.84)$ and remission $(0.57,95 \%$ CI $0.44-0.74)$, and reduced radiographic progression $(\mathrm{RR}=$ 0.91, 95\% CI 0.85-0.98) [25]. Further, incidence of serious adverse events, serious infection, malignancy, and scores of improvement of tender and swollen joints between these strategies were not significantly different.
About half of the patients withdrawing biologicals maintained low disease activity [25]. Similarly, an earlier study in 91 RA patients receiving the TNF- $\alpha$ inhibitor etanercept showed that a significantly higher number of patients stayed in remission with continued therapy vs. treatment withdrawal $(52 \%$ vs. $13 \% ; P=0.007)$. The latter group also had a very short time to failure (median of 6 weeks) as compared to those on full dose (48 weeks; $P=$ $0.001)$. Patients on continued therapy were more efficient in regaining remission after a flare-up [9].

The observed pooled relapse rate post-TNF- $\alpha$ inhibitor withdrawal in our study provides important quantitative data that complement existing information regarding relapse rates after discontinuation of other DMARD therapies in RA patients. The latter have been reported to be $40.0-78.9 \%$ with penicillamine [26, 27], 66.7\% with azathioprine [26, 28], 100\% with methotrexate [26, 29], $33.3 \%$ with gold [26], and $47.1 \%$ with sulphasalazine [26]. However, a direct comparison of relapse rates with

Table 4 Methodological quality of the non-RCTs as per CASP checklist

\begin{tabular}{|c|c|c|c|c|c|c|c|c|c|}
\hline$\overline{\mathrm{SI}}$ & Study Name & $\begin{array}{l}\text { Clearly } \\
\text { focused } \\
\text { issue }\end{array}$ & $\begin{array}{l}\text { Recruitment } \\
\text { acceptable }\end{array}$ & $\begin{array}{l}\text { Exposure } \\
\text { measured } \\
\text { accurately }\end{array}$ & $\begin{array}{l}\text { Outcome } \\
\text { measured } \\
\text { accurately }\end{array}$ & $\begin{array}{l}\text { Identified all } \\
\text { confounders }\end{array}$ & $\begin{array}{l}\text { Confounders } \\
\text { accounted for }\end{array}$ & $\begin{array}{l}\text { Follow-up } \\
\text { complete }\end{array}$ & $\begin{array}{l}\text { Follow up } \\
\text { long enough }\end{array}$ \\
\hline 1 & $\begin{array}{l}\text { Nawata et al., } \\
2008\end{array}$ & Yes & Yes & Yes & Yes & Yes & Yes & Yes & Yes \\
\hline 2 & $\begin{array}{l}\text { Brocq et al., } \\
2009\end{array}$ & Yes & Yes & Yes & Yes & Yes & Yes & Yes & Yes \\
\hline 3 & $\begin{array}{l}\text { Tanaka et al., } \\
2010\end{array}$ & Yes & Yes & Yes & Yes & Yes & Yes & Yes & Yes \\
\hline 4 & $\begin{array}{l}\text { van den Broek } \\
\text { et al., } 2011\end{array}$ & Yes & Yes & Yes & Yes & Yes & Yes & Cannot tell & Yes \\
\hline 5 & $\begin{array}{l}\text { van den Massk } \\
\text { et al., } 2012\end{array}$ & Yes & Yes & Yes & Yes & Yes & Yes & Yes & Yes \\
\hline 6 & $\begin{array}{l}\text { Harigai et al., } \\
2012\end{array}$ & Yes & Yes & Yes & Yes & Yes & Yes & Yes & Yes \\
\hline 7 & $\begin{array}{l}\text { Hirata et al., } \\
2013\end{array}$ & Yes & Yes & Yes & Yes & Yes & Yes & Yes & Yes \\
\hline 8 & $\begin{array}{l}\text { Iwamoto et al., } \\
2014\end{array}$ & Yes & Yes & Yes & Yes & Yes & Yes & Yes & Yes \\
\hline 9 & $\begin{array}{l}\text { Kádár et al., } \\
2014\end{array}$ & Yes & Yes & Yes & Yes & Yes & Yes & Yes & Yes \\
\hline 10 & $\begin{array}{l}\text { Tanaka et al., } \\
2015\end{array}$ & Yes & Yes & Yes & Yes & Yes & Yes & Yes & Yes \\
\hline 11 & $\begin{array}{l}\text { NCT00808509 } \\
\text { (ADMIRE) }\end{array}$ & Yes & Yes & Yes & Yes & Yes & Yes & Yes & Yes \\
\hline
\end{tabular}


Study name

Quinn et al., 2005

Nawata et al., 2008

Brocq et al., 2009

Tanaka et al., 2010

van den Broek et al., 2011

van den Massk et al., 2012

Harigai et al., 2012

Hirata et al., 2013

Smolen et al., 2013

Iwamoto et al., 2014

Kádár et al., 2014

Tanaka et al., 2015

Moghadam et al., 2016

NCT00808509 (ADMIRE)

NCT00858780 (DOSERA)

NCT00858780 (DOSERA) b

\begin{tabular}{ccc} 
Relapse & \multicolumn{2}{c}{ 95\% Cl } \\
(\%) & Lower & Uppe \\
0.30 & 0.10 & 0.62 \\
0.56 & 0.25 & 0.82 \\
0.75 & 0.52 & 0.89 \\
0.45 & 0.36 & 0.55 \\
0.46 & 0.37 & 0.56 \\
0.39 & 0.27 & 0.53 \\
0.68 & 0.47 & 0.84 \\
0.42 & 0.29 & 0.56 \\
0.57 & 0.50 & 0.64 \\
0.40 & 0.26 & 0.56 \\
0.15 & 0.06 & 0.32 \\
0.52 & 0.39 & 0.65 \\
0.51 & 0.47 & 0.55 \\
0.87 & 0.59 & 0.97 \\
0.17 & 0.04 & 0.48 \\
0.08 & 0.01 & 0.41 \\
0.47 & 0.41 & 0.54 \\
& &
\end{tabular}

Event rate and $95 \% \mathrm{Cl}$

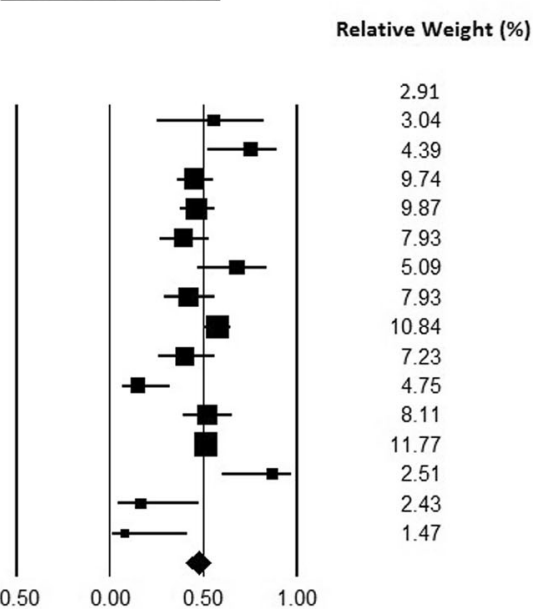

Fig. 2 Pooled relapse rates in RA patients after elective withdrawal of anti-TNF therapies

various DMARDs is rendered difficult because of the different baseline clinical characteristics, concomitant RA treatment, methods to assess relapse, and follow-up in individual studies. Furthermore, the RA treatment strategies investigated in these relatively old studies are quite different from those recommended by current professional guidelines.

All the studies included in this analysis, employing rigid criteria for measuring disease activity and monitoring remission, used improvement in DAS28 scoring system. This is a widely used and recommended criterion [30]. However, this in itself could be one of the key reasons for higher relapse rates. A recent conference paper showed that total dependence on DAS28 for monitoring complete remission may not be a reliable method to ensure that patients remain in remission [31]. This study used DAS28 to monitor disease activity and ACR/ EULAR 2010 criteria to measure response to therapy coupled with MRI for dominant joint erosions. $73 \%$ of the patients showing improvement in DAS28 score after 12 months also showed decrease in erosions, while $24 \%$ had increased erosions. $41 \%$ patients who attained remission as per EULAR score also had increased erosions. $40 \%$ of all the patients, despite showing improvements in DAS28 score, continued to undergo progressive erosive arthritis. It is highly likely that patients from the

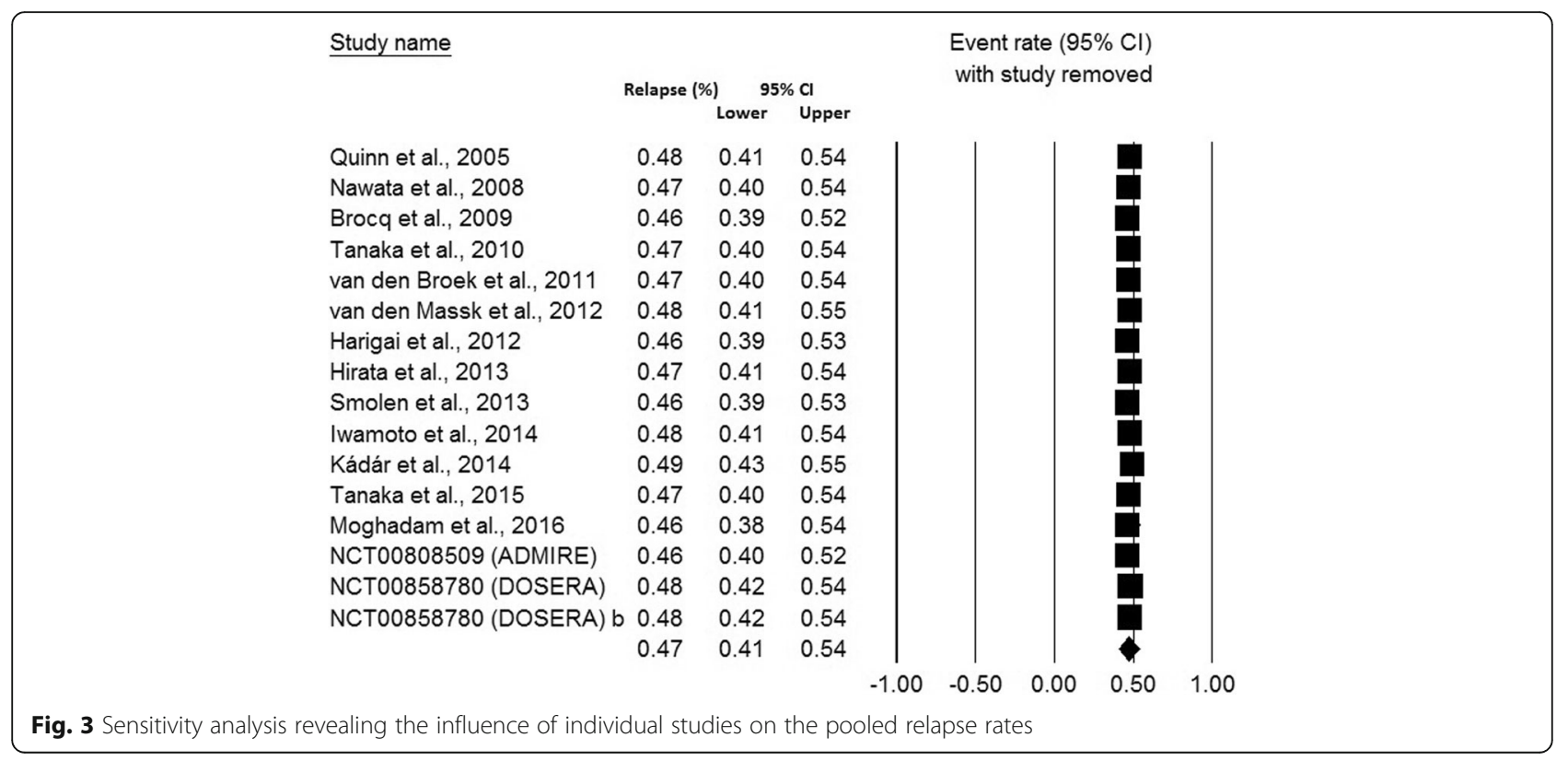




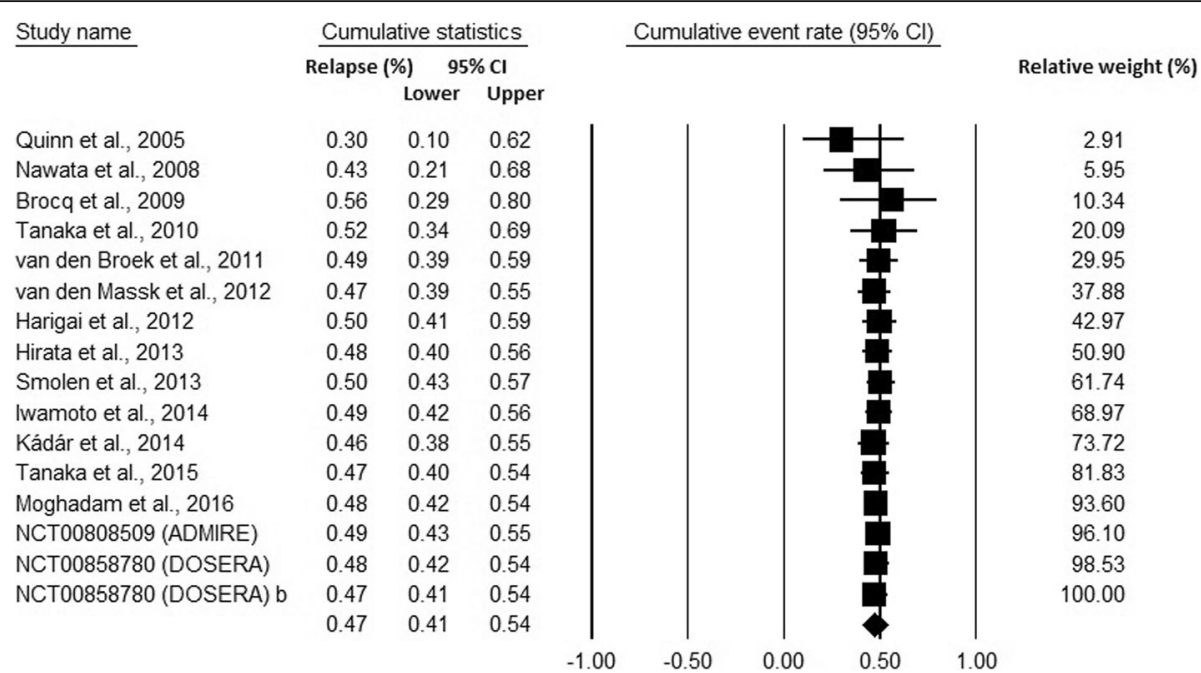

Fig. 4 Cumulative meta-analysis of trials studying relapse rates after elective withdrawal of anti-TNF therapy in RA patients

studies included in our analysis also had undergone continued erosions even after DAS28 improvements. As a result, it is possible that the relapse rate in 'real-life' is even higher than that $(47 \%)$ reported in our meta-analysis.

The results of our meta-analysis provide much needed information regarding the magnitude of the overall risk of relapse in RA patients receiving TNF- $\alpha$ inhibitor therapy, where treatment withdrawal is being considered by the patient and/or the treating physician. However, some caution is required when translating these results into routine clinical practice because of the differences between studies in the treatment duration with TNF- $\alpha$ inhibitors at baseline, the criteria used to define TNF- $\alpha$ inhibitor withdrawal eligibility and relapse, the concomitant treatment with other DMARDs, and the duration of follow-up. Further limitations include the relatively small sample size of the selected studies and the fact that relapse rates, not their severity, were investigated.

\section{Conclusions}

Our study shows that elective TNF- $\alpha$ inhibitor withdrawal in RA patients is associated with a relatively high relapse rate. This information should be taken into account when considering this management strategy. Further studies are required to identify whether specific patient characteristics, TNF- $\alpha$ inhibitors discontinued, or concomitant DMARDs independently predict the risk of relapse in this patient group.

\section{Funnel Plot of Standard Error by Logit event rate}

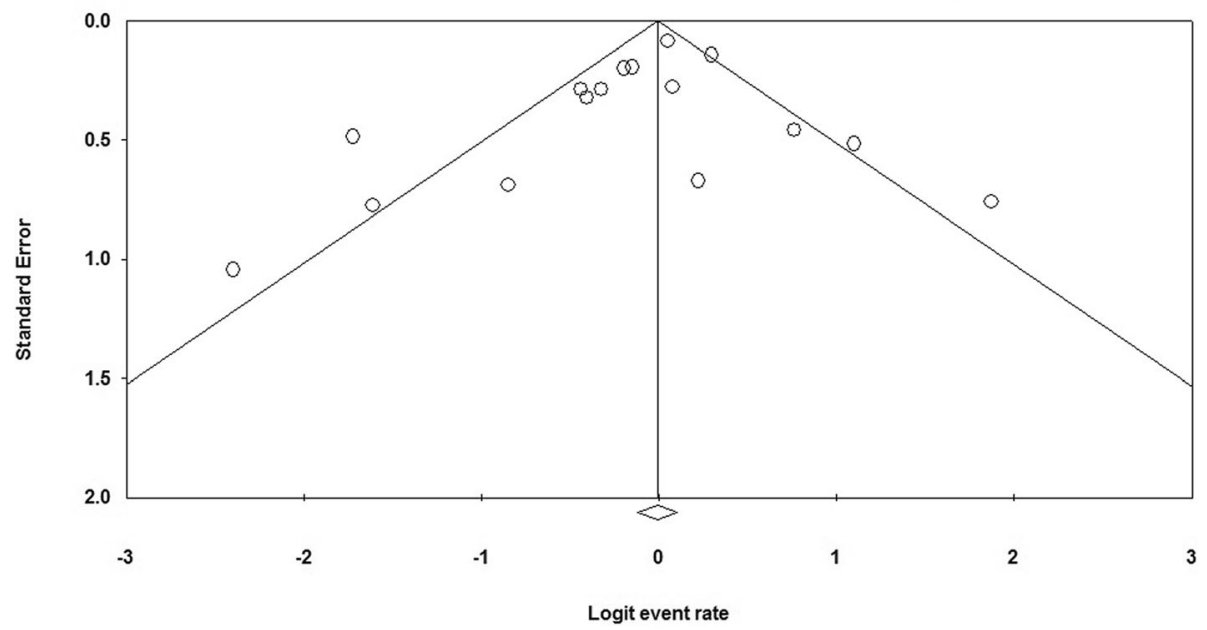

Fig. 5 Funnel plot of standard error by log odds ratio 


\section{Abbreviations}

ACR: American College of Rheumatology; ANA: Antinuclear antibody; CASP: The Critical Appraisal Skills Programme; Cl: Confidence Interval; DAS: Disease Activity Score; DMARD: Disease-modifying antirheumatic drug; EULAR: European League Against Rheumatism; MRI: Magnetic Resonance Imaging; NSAID: Nonsteroidal anti-inflammatory drug; RA: Rheumatoid arthritis; RCT: Randomised controlled trials; TNF-a: Tumor necrosis factor alpha; US: United States; WHO: World Health Organisation

\section{Acknowledgements}

The authors wish to acknowledge the medical writing, language editing, proofreading, and editorial assistance of Research-Medics in the preparation of the manuscript.

\section{Funding}

No funding received.

\section{Availability of data and materials}

Not applicable (not an original research study).

\section{Authors' contributions}

$A A M, F A O, H A, S A R$, RHAM, and $A B$ generated the research question. FAO and SAR conducted the literature search. AAM wrote the first draft of the manuscript. AAM, FAO, HA, SAR, RHAM, and AB reviewed all drafts and the analysis. All authors read and approved the final manuscript.

\section{Ethics approval and consent to participate}

Not applicable (systematic review).

\section{Consent for publication}

Not applicable (systematic review).

\section{Competing interests}

The authors declare that they have no competing interests.

\section{Publisher's Note}

Springer Nature remains neutral with regard to jurisdictional claims in published maps and institutional affiliations.

\section{Author details}

'Department of Clinical Pharmacology, Flinders University and Flinders Medical Centre, Bedford Park, SA 5042, Australia. ${ }^{2}$ Prince Sultan Military Medical City, Riyadh, Saudi Arabia. ${ }^{3}$ Department of Medicine, Umm Alqura University, Jeddah, Kingdom of Saudi Arabia. ${ }^{4}$ Rheumatology and Clinical Immunology, Department of Rheumatology and Rehabilitation, School of Medicine, Cairo University Hospitals, Cairo, Egypt. ${ }^{5}$ Internal Medicine Department, Alhada Armed Forces Hospital, Taif, Kingdom of Saudi Arabia. ${ }^{6}$ Department of Rheumatology and Rehabilitation, Tanta University Faculty of Medicine, Elgesh Street, Tanta, Gharbeia, Egypt.

Received: 6 June 2018 Accepted: 26 February 2019

Published online: 08 March 2019

\section{References}

1. Smolen JS, Aletaha D, McInnes IB. Rheumatoid arthritis. Lancet. 2016;388: 2023-38.

2. MacGregor AJ, Riste LK, Hazes JM, Silman AJ. Low prevalence of rheumatoid arthritis in black-Caribbeans compared with whites in inner city Manchester. Ann Rheum Dis. 1994:53:293-7.

3. Oliver JE, Silman AJ. Why are women predisposed to autoimmune rheumatic diseases? Arthritis Res Ther. 2009;11:252.

4. Geiler J, Buch M, McDermott MF. Anti-TNF treatment in rheumatoid arthritis. Curr Pharm Des. 2011;17:3141-54.

5. Atzeni F, Gianturco L, Talotta R, Varisco V, Ditto MC, Turiel M, et al. Investigating the potential side effects of anti-TNF therapy for rheumatoid arthritis: cause for concern? Immunotherapy. 2015;7:353-61.

6. Furst DE, Keystone EC, So AK, Braun J, Breedveld FC, Burmester GR, et al. Updated consensus statement on biological agents for the treatment of rheumatic diseases, 2012. Ann Rheum Dis. 2013;72(Suppl 2):ii2-34.

7. Aaltonen KJ, Virkki LM, Malmivaara A, Konttinen YT, Nordstrom DC, Blom M. Systematic review and meta-analysis of the efficacy and safety of existing
TNF blocking agents in treatment of rheumatoid arthritis. PLoS One. 2012;7: e30275.

8. Singh JA, Hossain A, Mudano AS, Tanjong Ghogomu E, Suarez-Almazor ME, Buchbinder $\mathrm{R}$, et al. Biologics or tofacitinib for people with rheumatoid arthritis naive to methotrexate: a systematic review and network metaanalysis. Cochrane Database Syst Rev. 2017;5:Cd012657.

9. van Vollenhoven RF, Ostergaard M, Leirisalo-Repo M, Uhlig T, Jansson M, Larsson E, et al. Full dose, reduced dose or discontinuation of etanercept in rheumatoid arthritis. Ann Rheum Dis. 2015;75:52-8.

10. Arnett FC, Edworthy SM, Bloch DA, McShane DJ, Fries JF, Cooper NS, et al. The American rheumatism association 1987 revised criteria for the classification of rheumatoid arthritis. Arthritis Rheum. 1988;31:315-24.

11. Aletaha D, Neogi T, Silman AJ, Funovits J, Felson DT, Bingham CO 3rd, et al. 2010 rheumatoid arthritis classification criteria: an American College of Rheumatology/European league against rheumatism collaborative initiative. Ann Rheum Dis. 2010;69:1580-8.

12. Oremus M, Wolfson C, Perrault A, Demers L, Momoli F, Moride Y. Interrater reliability of the modified Jadad quality scale for systematic reviews of Alzheimer's disease drug trials. Dement Geriatr Cogn Disord. 2001;12:232-6.

13. Zeng $X$, Zhang Y, Kwong JS, Zhang C, Li S, Sun F, et al. The methodological quality assessment tools for preclinical and clinical studies, systematic review and meta-analysis, and clinical practice guideline: a systematic review. J Evid Based Med. 2015:8:2-10.

14. Sutton AJ, Abrams KR, Jones DR, Jones DR, Sheldon TA, Song F. Methods for meta-analysis in medical research: Wiley Chichester; 2000.

15. DerSimonian R, Laird N. Meta-analysis in clinical trials. Control Clin Trials. 1986:7:177-88.

16. Cochran KW, Brown GC, Francis T Jr. Antiviral action of a mold filtrate on experimental poliomyelitis in cynomolgus monkeys. Proc Soc Exp Biol Med. 1954:85:104-6.

17. Higgins JP, Thompson SG. Quantifying heterogeneity in a meta-analysis Stat Med. 2002;21:1539-58.

18. Light RJ, Pillemer DB. Summing up: The science of reviewing research. Cambridge: Harvard University; Press. 1984.

19. Duval S, Tweedie R. Trim and fill: a simple funnel-plot-based method of testing and adjusting for publication bias in meta-analysis. Biometrics. 2000; 56:455-63.

20. Bolge SC, Goren A, Tandon N. Reasons for discontinuation of subcutaneous biologic therapy in the treatment of rheumatoid arthritis: a patient perspective. Patient Prefer Adherence. 2015:9:121-31.

21. Ramiro S, Landewe R, van der Heijde D, Harrison D, Collier D, Michaud K. Discontinuation rates of biologics in patients with rheumatoid arthritis: are TNF inhibitors different from non-TNF inhibitors? RMD Open. 2015;1:e000155.

22. Hetland ML, Christensen IJ, Tarp U, Dreyer L, Hansen A, Hansen IT, et al. Direct comparison of treatment responses, remission rates, and drug adherence in patients with rheumatoid arthritis treated with adalimumab, etanercept, or infliximab: results from eight years of surveillance of clinical practice in the nationwide Danish DANBIO registry. Arthritis Rheum. 2010; 62:22-32

23. Gomez-Reino JJ, Carmona L, Group B. Switching TNF antagonists in patients with chronic arthritis: an observational study of 488 patients over a fouryear period. Arthritis Res Ther. 2006;8:R29.

24. Kuijper TM, Lamers-Karnebeek FB, Jacobs JW, Hazes JM, Luime JJ. Flare rate in patients with rheumatoid arthritis in low disease activity or remission when tapering or stopping synthetic or biologic DMARD: a systematic review. J Rheumatol. 2015;42:2012-22.

25. Galvao TF, Zimmermann IR, da Mota LM, Silva MT, Pereira MG. Withdrawal of biologic agents in rheumatoid arthritis: a systematic review and metaanalysis. Clin Rheumatol. 2016;35(7):1659-68.

26. ten Wolde S, Breedveld FC, Hermans J, Vandenbroucke JP, van de Laar MA, Markusse HM, et al. Randomised placebo-controlled study of stopping second-line drugs in rheumatoid arthritis. Lancet. 1996:347:347-52.

27. Ahern MJ, Hall ND, Case K, Maddison PJ. D-penicillamine withdrawal in rheumatoid arthritis. Ann Rheum Dis. 1984:43:213-7.

28. De Silva M, Hazleman BL. Long-term azathioprine in rheumatoid arthritis: a double-blind study. Ann Rheum Dis. 1981:40:560-3.

29. Kremer JM, Rynes RI, Bartholomew LE. Severe flare of rheumatoid arthritis after discontinuation of long-term methotrexate therapy. Double-blind study. Am J Med. 1987;82:781-6.

30. Prevoo ML, van 't Hof MA, Kuper $H H$, van Leeuwen $M A$, van de Putte LB, van Riel PL. Modified disease activity scores that include twenty-eight-joint 
counts. Development and validation in a prospective longitudinal study of patients with rheumatoid arthritis. Arthritis Rheum. 1995;38:44-8.

31. Sewerin P, Vordenbaeumen S, Hoyer A, Brinks R, Buchbender C, Miese F, et al. Silent progression in patients with rheumatoid arthritis: is DAS28 remission an insufficient goal in RA? Results from the German Remissionplus cohort. BMC Musculoskelet Disord. 2017;18:163.

32. Quinn MA, Conaghan PG, O'Connor PJ, Karim Z, Greenstein A, Brown A, et al. Very early treatment with infliximab in addition to methotrexate in early, poor-prognosis rheumatoid arthritis reduces magnetic resonance imaging evidence of synovitis and damage, with sustained benefit after infliximab withdrawal: results from a twelve-month randomized, doubleblind, placebo-controlled trial. Arthritis Rheum. 2005;52:27-35.

33. Nawata M, Saito K, Nakayamada S, Tanaka Y. Discontinuation of infliximab in rheumatoid arthritis patients in clinical remission. Mod Rheumatol. 2008;18: 460-4.

34. Brocq O, Millasseau E, Albert C, Grisot C, Flory P, Roux CH, et al. Effect of discontinuing TNFalpha antagonist therapy in patients with remission of rheumatoid arthritis. Joint Bone Spine. 2009;76:350-5.

35. Tanaka Y, Takeuchi T, Mimori T, Saito K, Nawata M, Kameda H, et al. Discontinuation of infliximab after attaining low disease activity in patients with rheumatoid arthritis: RRR (remission induction by Remicade in RA) study. Ann Rheum Dis. 2010;69:1286-91.

36. van den Broek M. Treat to target in rheumatoid arthritis : opportunities and outcomes [doctoral thesis]: Leiden University; 2013.

37. van der Maas A, Kievit W, van den Bemt BJ, van den Hoogen FH, van Riel $\mathrm{PL}$, den Broeder AA. Down-titration and discontinuation of infliximab in rheumatoid arthritis patients with stable low disease activity and stable treatment: an observational cohort study. Ann Rheum Dis. 2012;71:1849-54.

38. Harigai M, Takeuchi T, Tanaka Y, Matsubara T, Yamanaka H, Miyasaka N. Discontinuation of adalimumab treatment in rheumatoid arthritis patients after achieving low disease activity. Mod Rheumatol. 2012;22:814-22.

39. Hirata S, Saito K, Kubo S, Fukuyo S, Mizuno Y, Iwata S, et al. Discontinuation of adalimumab after attaining disease activity score 28-erythrocyte sedimentation rate remission in patients with rheumatoid arthritis (HONOR study): an observational study. Arthritis Res Ther. 2013;15:R135.

40. Smolen JS, Nash P, Durez P, Hall S, llivanova E, Irazoque-Palazuelos F, et al. Maintenance, reduction, or withdrawal of etanercept after treatment with etanercept and methotrexate in patients with moderate rheumatoid arthritis (PRESERVE): a randomised controlled trial. Lancet. 2013;381:918-29.

41. Iwamoto T, Ikeda K, Hosokawa J, Yamagata M, Tanaka S, Norimoto A, et al. Prediction of relapse after discontinuation of biologic agents by ultrasonographic assessment in patients with rheumatoid arthritis in clinical remission: high predictive values of total gray-scale and power Doppler scores that represent residual synovial inflammation before discontinuation. Arthritis Care Res. 2014;66:1576-81.

42. Kadar G, Balazs E, Soos B, Laduver A, Keszthelyi P, Szekanecz Z, et al. Disease activity after the discontinuation of biological therapy in inflammatory rheumatic diseases. Clin Rheumatol. 2014;33:329-33.

43. Tanaka Y, Hirata S, Kubo S, Fukuyo S, Hanami K, Sawamukai N, et al. Discontinuation of adalimumab after achieving remission in patients with established rheumatoid arthritis: 1-year outcome of the HONOR study. Ann Rheum Dis. 2015;74:389-95.

44. Ghiti Moghadam M, Vonkeman HE, Ten Klooster PM, Tekstra J, van Schaardenburg D, Starmans-Kool M, et al. Stopping Tumor Necrosis Factor Inhibitor Treatment in Patients With Established Rheumatoid Arthritis in Remission or With Stable Low Disease Activity: A Pragmatic Multicenter, OpenLabel Randomized Controlled Trial. Arthritis Rheumatol. 2016;68:1810-7.

Ready to submit your research? Choose BMC and benefit from:

- fast, convenient online submission

- thorough peer review by experienced researchers in your field

- rapid publication on acceptance

- support for research data, including large and complex data types

- gold Open Access which fosters wider collaboration and increased citations

- maximum visibility for your research: over $100 \mathrm{M}$ website views per year

At BMC, research is always in progress.

Learn more biomedcentral.com/submissions 